\title{
A "mãe do corpo": conhecimentos das mulheres Karipuna e Galibi-Marworno sobre gestação, parto e puerpério
}

The "mother body": Karipuna and Galibi-Marworno women knowledge about pregnancy, childbirth and puerperium

\author{
Antonella Tassinari' \\ https://orcid.org/0000-0002-8649-7593 \\ antonella.tassinari@gmail.com \\ I Universidade Federal de Santa Catarina - Florianópolis, SC, Brasil
}




\title{
Resumo
}

O artigo analisa um conjunto de conhecimentos, técnicas e cuidados relativos à gestação, parto e puerpério, utilizados por uma rede de mulheres Karipuna e Galibi-Marworno do vale do rio Uaçá, Oiapoque (AP), experientes em "puxar barriga” (halevã). Busca-se mostrar que essa atividade articula compreensões dessas duas populações sobre fertilidade, saúde da mulher, gestação, parto e infância, enunciadas em torno do conceito da "mãe do corpo". Ao dar relevo ao período imediatamente anterior e posterior ao nascimento, pretende-se lançar luz sobre essa fase da infância, pouco estudada, mostrando que, assim como para as crianças maiores, sua agência e vontade são também reconhecidas pelos adultos. Ao expor a composição de uma rede supraétnica de circulação de conhecimentos femininos, pretende-se contribuir para uma reflexão sobre modos de aprendizagem, noções de pessoa, corporalidade e infância.

Palavras-chave: Karipuna; Galibi-Marworno; corporalidade; gestação.

\begin{abstract}
The article analyzes a set of knowledge, techniques and care related to pregnancy, childbirth and puerperium, used by a network of Karipuna and Galibi-Marworno women from the Uaçá river valley, Oiapoque (AP), experts in "pulling the belly" (halevã). It aims to show this activity articulates understandings of these two populations about fertility, women's health, pregnancy, childbirth and childhood, enunciated around the concept of the "mother body". By emphasizing the period immediately before and after birth, it is intended to shed light on this childhood phase, which has been little studied, and to show its agency and dispositions are also recognized by adults, as it happens with older children. By presenting the composition of a supra-ethnic network for the circulation of female knowledge, the article aims to provide a reflection on modes of learning, notions of person, corporeity and childhood.
\end{abstract}

Keywords: Karipuna; Galibi-Marworno; corporeity; pregnancy. 


\section{Introdução ${ }^{1}$}

Na escuridão da noite, no meio do rio Curipi, um choro de criança recém-nascida rompe o silêncio. O choro vinha da voadeira da enfermaria da aldeia Açaizal, parada no meio do rio, onde acabara de nascer o bebê que havia feito sua mãe esperar dois dias em trabalho de parto. Ele resolvera nascer ali perto da aldeia Espírito Santo, a caminho da cidade do Oiapoque. Quem fez o parto foi Jaqueline, técnica de enfermagem, iluminada por uma lanterna de cabeça, furou a bolsa e segurou o bebê ali mesmo no barco. Ela é Karipuna, filha e neta de mulheres experientes em puxar barriga, nascida e criada na aldeia Manga, a mais populosa e movimentada aldeia indígena do Oiapoque, por ser a mais próxima e de fácil acesso à cidade. Jaqueline trabalha há dois anos na enfermaria de Açaizal e é sempre chamada para acompanhar os partos, por respeitar os conhecimentos e práticas das mulheres experientes e só intervir quando lhe solicitam. Ela se surpreendeu ao ver que ali se mantêm antigas técnicas de partejar, como ser papel da mãe cortar o cordão umbilical do bebê, usando uma ponta de flecha preparada pelo pai durante a gestação. As mulheres mais antigas já não fazem mais parto em Açaizal e as que estão atuando agora aprenderam com mulheres experientes da aldeia Espírito Santo e fizeram também cursos de parteiras promovidos pelo estado do Amapá. Ficaram inseguras, depois de dois dias acompanhando o trabalho de parto de uma jovem mãe, pois aprenderam nos cursos que poderiam ser responsabilizadas em caso de morte do bebê ou da parturiente, então pediram que Jaqueline a levasse para o hospital da cidade de Oiapoque, que fica a uma hora em viagem de voadeira e mais uma hora por estrada de terra. Jaqueline acha que a mãe estava com medo e não liberava a criança, pois, em meia hora na voadeira, o bebê começou a nascer. Não havia panos para envolvê-lo, então utilizaram os plásticos do barco para agasalha-lo até chegar na enfermaria da aldeia Espírito Santo. Ali, ele e a mãe receberam os cuidados da equipe de enfermagem e das mulheres experientes da aldeia, que haviam preparado aquelas de Açaizal. A mãe e a criança ficaram bem e, em poucas horas, Jaqueline retornou para a aldeia Açaizal. (Narrativa reconstruída a partir de conversa com Jaqueline dos Santos na enfermaria da aldeia Açaizal, 14/02/2020).

1 O presente trabalho foi realizado com o apoio do CNPq, processo número 308259/2018-1, e do INCT Brasil Plural. 
Esse episódio sintetiza uma questão central tratada neste artigo, a respeito de conhecimentos, técnicas e cuidados das mulheres Karipuna e Galibi-Marworno experientes em "puxar barriga": elas compõem uma rede de aprendizagem e cooperação que extrapola a pertença a aldeias ou etnias e que estão em relação estreita com agentes do sistema público de saúde, ora de forma conflituosa, ora de forma colaborativa. A composição dessa rede é o alicerce para o que se pretende explicitar no artigo: a forma atual como as mulheres Karipuna e Galibi-Marworno colocam em prática saberes sobre fertilidade, saúde da mulher, técnicas relacionadas à gestação, parto e puerpério, articuladas em torno da ideia de "mãe do corpo".

Destacam-se as "puxações de barriga" (halevã) feitas nas mulheres, para colocar a mãe do corpo no lugar e restabelecer sua saúde e fertilidade ou para acompanhar a gestação, endireitar o bebê e colocá-lo na posição correta, assim como os cuidados na hora do parto e puerpério, as dietas e resguardos da quarentena e as massagens feitas nos bebês recém-nascidos (aple laxe), para "chamar a carne" e fazê-los crescer forte e saudáveis. Observa-se, nesses processos, uma atenção e reconhecimento das iniciativas, atitudes e disposições do feto e do recém-nascido, inclusive em seu processo de nascimento, do mesmo modo que tem sido apontado em relação às crianças maiores (Tassinari, 2007).

As técnicas de puxar barriga são encontradas em diversas regiões do Brasil, geralmente associadas à noção de mãe do corpo e, às vezes, também relacionadas a histórias de gestações causadas por animais "encantados" ou seres invisíveis, como é o caso da região do Uaçá. As semelhanças das descrições apresentadas na tese de Soraya Fleischer (2007) sobre uma comunidade ribeirinha em Melgaço (PA) e na tese de Raquel Scopel (2014), a respeito da gestação, parto e pós-parto entre os Munduruku (AM), com o contexto etnográfico aqui descrito, indicam um complexo de conhecimentos femininos amplamente difundidos na região amazônica entre populações indígenas e afro-ribeirinhas. O trabalho de Julia Sauma (2019), junto a uma comunidade quilombola no rio Erepecuru, próximo a Oriximiná (PA), e a tese de Fernando Fileno (2017), a respeito dos Mura da região de Borba (AM), numa área próxima à dos Munduruku pesquisados por Scopel, reforçam essa ideia de uma circulação de saberes entre populações indígenas, quilombolas e ribeirinhas. A dissertação de Luiza Garnelo Pereira (1993 apud Mindlin, 2002) realizada 
entre parteiras tradicionais em Manaus também faz referência à mãe do corpo, revelando que essa circulação atinge camadas populares de contextos urbanos.

Pesquisa bibliográfica sobre gestação e parto indígenas, realizada por Mariana Ribeiro dos Santos (2019), indica que essas práticas são encontradas em populações indígenas para além do contexto amazônico. A autora encontrou uma referência à mãe do corpo na pesquisa de Verone Silva (2015 apud Santos, 2019) entre os Chiquitano (MT), na região da fronteira entre Brasil e Bolívia, e uma referência, na tese de Lilian de Lima (2016 apud Santos, 2019), à puxação de barriga entre os Apinajé, na região próxima a Tocantinópolis (TO). Embora essas referências indiquem uma ampla circulação de conhecimentos femininos sobre gestação, parto e puerpério, quando se fala do ofício de parteiras há uma tendência em obliterar a importância das puxações e concepções sobre o corpo e a destacar o momento do parto.

Os conhecimentos femininos de mulheres experientes em partejar têm sido reconhecidos por recomendações da Organização Mundial da Saúde (OMS) desde meados de 1980 e pelo Estado brasileiro na década seguinte (Tornquist, 2005). No estado do Amapá, o Programa de Desenvolvimento Sustentável (PDSA) de 1995 já previa o Programa das Parteiras Tradicionais, criado por iniciativa de Janete Capiberibe, então deputada estadual (Mindlin, 2002), com o objetivo de valorizar o conhecimento popular de parteiras e diminuir a mortalidade infantil e materna. Esse programa, pelo seu pioneirismo e articulações nacionais e internacionais, é uma das referências do movimento pelo parto humanizado (Tornquist, 2004). ${ }^{2}$

No entanto, algumas práticas realizadas por parteiras tradicionais são classificadas pela mesma OMS como "perigosas", dentre elas as puxações, o corte do cordão umbilical e a cicatrização do umbigo do recém-nascido (Fleischer, 2007). Aí reside a ambiguidade das ações governamentais voltadas para a formação e reconhecimento das parteiras, que acabam estimulando e formatando algumas práticas enquanto desestimulam e/ou proíbem outras.

2 Em 1998, o Programa foi uma das 20 experiências premiadas pelo Programa Gestão Pública e Cidadania (Fundação Getúlio Vargas, Fundação Ford e BNDES) (Laczynski, 1999) e, no mesmo ano, recebeu o Prêmio Paulo Freire por sua inovação (Capiberibe, 2002). 
Concordo com a avaliação de Tornquist (2005), de que, apesar da importância das políticas públicas de reconhecimento e valorização da parteira tradicional, faz-se necessário um olhar atento às práticas e conhecimentos dessas mulheres e um "descentramento do nosso olhar - tão comprometido com os parâmetros modernos - a partir do contato com a alteridade que está presente nas práticas das parteiras populares" (Tornquist, 2005, p. 77). Nesse sentido, 0 artigo pretende contribuir em três aspectos, a partir de um descentramento de nosso olhar e uma atenção aos conhecimentos das mulheres Karipuna e Galibi-Marworno: descentrar o parto como atividade principal dessas parteiras (ao focalizar a puxação de barriga e os conhecimentos relativos à mãe do corpo como centrais), descentrar o nascimento como início da infância, reconhecer as redes de aprendizagem e cooperação por onde circulam esses saberes.

Sobre a metodologia da pesquisa, venho realizando pesquisas entre os Karipuna desde 1990 e, com os Galibi-Marworno, a partir de 2001. ${ }^{3}$ Iniciei uma investigação mais sistemática sobre circulação de conhecimentos femininos, gestação e parto a partir de janeiro de 2010 , quando realizei trabalho de campo entre os Galibi-Marworno. Na ocasião, entrevistei 11 mulheres que sabem puxar barriga e/ou fazer partos, sendo nove na aldeia Kumarumã, uma na aldeia Tukai e uma na cidade de Oiapoque. A pesquisa na aldeia também abarcou observação participante, filmagem das atividades das crianças, da puxação de barriga, das massagens em bebês, conversas com lideranças familiares sobre a educação das crianças. Na cidade, também entrevistei a presidente da Associação das Mulheres Indígenas em Mutirão (AMIM) e um técnico em enfermagem Karipuna atuante no hospital de Oiapoque. Em janeiro de 2016, retornei para a aldeia de Kumarumã, onde fiz a devolução de fotografias e vídeos da pesquisa anterior, visitei as novas aldeias que estavam sendo fundadas no rio Uaçá, onde fiz mais filmagens da puxação de barriga. Nessa ocasião, realizei entrevistas com 14 mulheres Karipuna que sabem puxar barriga e/ou partejar, sendo cinco na aldeia Manga, duas em Santa Isabel, duas em Espírito Santo,

3 Ao longo desses anos, num total de 12 meses em campo, realizei pesquisas sobre diversos temas, como festas, rituais, organização social, história, educação, infância e escolarização (Tassinari 2003, 2011, 2015; Tassinari; Cohn, 2009), importantes para melhor compreender e contextualizar a pesquisa apresentada no presente artigo. 
uma em Pacapuwa, uma no Txipidon, uma no Taminã e duas em Ariramba. Também entrevistei uma técnica em enfermagem e um médico que atuavam na aldeia Manga. Em janeiro de 2020 entrevistei novamente uma senhora Galibi-Marworno e sua filha, técnica de enfermagem, na cidade de Oiapoque e, na aldeia Açaizal, uma antiga parteira e uma técnica de enfermagem Karipuna. Optei por apresentar os nomes das pessoas entrevistadas, considerando que manifestaram desejo de reconhecimento público de seu trabalho e suas contribuições.

Na sequência do artigo faço uma reflexão sobre a antropologia da criança e a recente atenção à vida dos bebês e do feto, procurando evidenciar a relação entre o tema da gestação, parto e puerpério num debate sobre infância. Um segundo item discute a noção de mãe do corpo para as mulheres Karipuna e Galibi-Marworno, mostrando a importância de defini-la segundo concepções próprias e não meramente traduzíveis por "útero". Um terceiro item procura apresentar - a partir do contexto histórico, regras de parentesco e modos próprios de aprendizagem, como se dá a composição de uma rede supraétnica de mulheres experientes em puxar barriga, nos termos de uma comunidade de prática (Lave; Wenger, 1991). O quarto item apresenta a técnica de halevã usada tanto em não gestantes, para colocar a mãe do corpo no lugar, quanto em gestantes, para direcionar o bebê para o lugar do nascimento, considerando que essa técnica é o que define a expertise das "mulheres experientes em puxar barriga". O último item trata dos cuidados do parto, do puerpério e da quarentena, incluindo as massagens aple laxe, para "puxar a carne" e "fazer o corpo do bebê", com destaque para o reconhecimento da agência da criança nesses momentos.

\section{Reconhecendo a agência dos bebês}

A atenção à vida dos bebês é tema muito recente na antropologia. Mais ainda é o reconhecimento da vida intrauterina como fase da infância passível de ser estudada antropologicamente. Alma Gottlieb (2012) em sua bela monografia sobre a cultura dos recém-nascidos beng da Costa do Marfim, discute a falta de interesse da antropologia geral e, particularmente, da antropologia cultural, na vida dos bebês. Em certa parte, atribui esse desinteresse às dificuldades metodológicas de se comunicar com as crianças pequenas demonstrando que, quanto menor 
a criança, menos atenção recebe de nossa área de investigação. Dentre os motivos elencados pela autora para essa falta de atenção da antropologia aos bebês, destaco o fato de serem geralmente compreendidos como o que ela chama de "biopacote", ou seja, seres "pré-culturais" envolvidos com emanações dos processos biológicos de seu funcionamento corporal. Ao contrário, a autora advoga que:

Hoje, entretanto, processos biologicamente influenciados, como sexualidade, amamentação, menstruação e ato de comer, têm sido identificados como assuntos apropriados para o olhar da antropologia cultural. Com efeito, a noção dos sentidos e do corpo em geral como culturalmente construídos é uma proposta séria. De acordo com essas mudanças teóricas, sugiro que é hora de a expressão somática dos bebês ser levada a sério pela nossa disciplina. O modelo ocidental prevalecente de bebê como biopacote é de fato aplicável universalmente? A visão Beng de bebê como um exílio reencarnado de outro mundo sugere o contrário. Enquanto eles são aparentemente indefesos e totalmente corporais, no modelo Beng de ciclo de vida os bebês de colo detêm uma rica vida interior. (Gottlieb, 2012, p. 109).

A autora procura substituir uma ideia de que os bebês são seres pré-culturais que respondem ao ambiente de acordo com suas necessidades e predisposições biológicas por uma abordagem atenta aos vínculos estabelecidos pelos bebês com suas cuidadoras e com seu entorno, de maneira a compreender a complexidade de sua vida cultural. O pressuposto da antropologia da criança (Cohn, 2005), que critica o tratamento universal dado à infância e reivindica o seu reconhecimento enquanto uma variável construída contextualmente, é aqui estendido para a pequena infância, demonstrando que as próprias definições de fases - como "bebês" ou "recém-nascidos" - devem ser também compreendidas em suas expressões locais.

A resenha de Cristina Toren (2004) à versão original do citado livro, embora ressalte a importância de se dar atenção à vida dos bebês, questiona a própria distinção entre natureza e cultura que estaria por trás do reconhecimento dos recém-nascidos como "seres culturais" advogado por Gottlieb (2012).

So, to reiterate one of Alma Gottlieb's questions: do babies have culture? My answer is no, generally speaking they don't. But it's not just because babies are babies that culture escapes them. Only those of us who take culture for granted 
as an idea (and perhaps particularly as an explanation) could be said to have culture. (Toren, 2004, p. 177).

Nessa crítica, Cristina Toren (2004) não está problematizando o reconhecimento dos bebês enquanto participantes ativos da vida sociocultural de suas famílias e comunidades, que Alma Gottlieb (2012) tão bem apresenta. Sua crítica repousa na necessidade de afirmar que seres humanos são culturais ou que certas ideias são construídas culturalmente, o que seria um "truísmo da antropologia cultural contemporânea" (Toren 2004, p. 176, tradução minha). A abordagem proposta por Toren (2012) questiona a distinção entre as dimensões biológicas e culturais do ser humano, propondo uma análise "unificada" que considere que o desenvolvimento do organismo ocorre, desde o início, imerso em relações socioculturais que o produzem, sendo impossível destacar aspectos "meramente biológicos" no ser humano. Em sua definição da ontogenia humana como um processo social, a autora aponta para o fato de que o processo de vida do organismo humano só é possível em interações sociais que estão presentes e o informam desde antes do nascimento:

Em outras palavras, qualquer ser humano é, em todos os aspectos de seu ser, um produto transformador dinâmico do passado por ele vivido e está situado em relação a todos os outros (jovens e velhos, vivos e mortos) cujas ideias e práticas estejam contribuindo para estruturar as condições de sua existência presente. "Qualquer ser humano", significa, aqui, qualquer feto, neonato, bebê, criança, adolescente, adulto ou idoso, porque a autopoiese é um processo que se inicia na concepção e só termina com a morte. (Toren, 2012, p. 22).

É nessa medida que a autora reconhece que a vida intrauterina pode ser também analisada pela antropologia, sendo um momento de interação do feto com o corpo da mãe e, através dele, com seu entorno social. Para Toren (2014), essa experiência anterior ao nascimento dá corpo a uma série de "esquemas" (aqui entendidos no sentido piagetiano ${ }^{4}$ ) que já nascem com o bebê e informam seu

4 Segundo Toren (2014, p. 402): “As used by Piaget the term 'schema' refers to a dynamic, self-producing system that is differentiated in functioning; its constitution over time is an aspect of the functioning of the embodied nervous system (it is not confined to the brain)." 
comportamento, sendo geralmente tomados como "naturais". Esses esquemas não são "representações mentais", mas se constroem com base no desenvolvimento de um sistema nervoso sensorial espraiado por todo o corpo e envolvendo todos os sentidos.

What we now know of sensory development and the capacities of neonates and young infants, suggests not only that before birth the child's experience is structured by the rhythms and practices of the mother's quotidian existence but also that what cognitive psychologists take to be universal schemas are bound to be differentiated in use over time as a function of the intersubjective relations in which they are engaged. (Toren, 2014, p. 404).

Isso implica reconhecer que muitas das atitudes dos bebês recém-nascidos tidas como "inatas" e, por isso, "naturais", podem ser atribuídas a esquemas construídos a partir da experiência sensorial intrauterina, na interação com 0 corpo da mãe, com suas atividades, ritmos e relações.

Em consonância com esses argumentos, alguns trabalhos têm ressaltado uma compreensão indígena da vida intrauterina como uma fase ativa, alargando a definição de infância para abarcar não só os bebês como também os fetos em gestação. O trabalho de Platt (2009), por exemplo, indica que os quéchuas da Bolívia reconhecem no feto aspectos de alteridade e agressividade que podem colocar a vida da mãe em risco, se não forem tomados certos cuidados.

A monografia de Veríssimo (2020), ao tratar das fases da infância entre seu povo Guarani, prefere apresentá-las no interior de um ciclo de vida, que abarca também a fase da gestação. Nesse ciclo, a autora identifica cinco fases que corresponderiam à infância (kyringue ou mitakuery) e a gravidez (puru'a régua) é uma delas, conforme explica:

Ipuru'a régua - gravidez antes do nascimento, dentro do ventre da sua mãe, mas já é um ser com espírito preparando para o mundo. Quando falamos sobre nossas crianças [e] fazemos reflexão sobre o mundo dos nossos bebês, não poderíamos esquecer-nos de falar sobre a nossa gravidez, [porque] antes de tudo com nossas crenças e religiosidade, a gravidez é um presente de Nhanderu Tenonde. [...] Então, é importante falar dos cuidados que mulher deve ter durante [o] 
processo da sua gravidez, porque acreditamos que um espírito de uma criança é puro, é ele que nos escolhe para vir ao mundo em que vivemos e já o consideramos um ser quando está dentro da barriga da mãe, que representa muito para nós também dentro nossa religião. Todos os cuidados são necessários para que a criança venha nascer com alegria e saúde para sua família. (Veríssimo, 2020, p. 20, grifo da autora).

Os recém-nascidos são também chamados pelos Guarani de "vermelhinhos" (mita'pytã), de modo semelhante ao que Pereira (2013) menciona entre os Piratapuia no rio Negro e mesmo Gottlieb (2012) encontrou entre os beng da Costa do Marfim. Os bebês de colo (mitaguaxu va`e) são uma fase em que as crianças ainda precisam da atenção da mãe ou de cuidadores. Kyringuaxu oguata va'e é outra fase, "quando a criança aprende a brincar a jogar [e] já [é] visível a interação social e sua comunicação com pessoas de toda a idade" (Veríssimo, 2020, p. 21), ressaltando que essa brincadeira (nhevãga) da pequena infância é considerada sagrada. A última fase antes da puberdade já faz distinções de gênero: ava’i (masculino) e kunha’i (feminino), fase de maior autonomia e aquisição de responsabilidades e aprendizagem dos conhecimentos relativos a cada gênero.

Sobre os períodos da infância entre os Galibi-Marworno, Codonho (2007) identifica três fases antes da puberdade: a primeira, tximimi, vai do nascimento até os 3 anos, e corresponde a um período em que o bebê é dependente de seus cuidadores; a segunda, mimi, vai dos 3 aos 6 anos aproximadamente, na qual a criança não tem responsabilidades, brinca com as crianças de seu $h \tilde{a}$, mas já acompanha os pais e irmãos em atividades cotidianas; e a terceira fase, que vai dos 7 aos 12 anos aproximadamente, é diferenciada por gênero: txiuom e txifam (que literalmente significam homenzinho e mulherzinha, mas são traduzidos por menino e menina). É uma fase de aumento de responsabilidades e preparação para a vida adulta. Todas essas fases podem ser também chamadas de tximun (singular) e tximun-iela (plural), termo genérico para "crianças". Segundo minhas observações de campo, essa mesma classificação é utilizada pelos Karipuna.

Mesmo não sendo nominada como uma das fases da infância, Codonho (2007) já observava que a existência da criança Galibi-Marworno antecede o seu nascimento, tendo seu protagonismo reconhecido desde a gestação. O seu 
reconhecimento como pessoa ocorre por volta dos 4 a 5 meses de gestação, quando seus olhos começam a se formar e sua nam (que pode ser traduzida por "alma", "espírito" ou "princípio vital") toma assento no pequeno corpo em formação. Esse espírito vai se desenvolvendo com o corpo do bebê e é considerado como "a força que faz nascer", dando à criança a força necessária para seu nascimento. Os cuidados com a construção do corpo do bebê iniciam nessa fase, não apenas com a puxação de barriga, mas também por meio de restrições e prescrições alimentares.

Com será tratado adiante, as mulheres experientes em puxar barriga estabelecem contato com esse bebê e o monitoram. D. Josefa, da aldeia Pacapuwa, por exemplo, diz que a criança sente seu toque e reage a ele. Ela usa um dente de alho para empurrar lentamente a criança e endireitá-la no ventre da mãe. Quer me parecer que tratam os bebês, antes e depois do nascimento, com o mesmo respeito e reconhecimento por suas ações, opções e vontades, que dedicam às crianças maiores, como procurei descrever em outro trabalho (Tassinari, 2015).

\section{A mãe do corpo}

Mamã pitxit é o termo em kheuol, ${ }^{5}$ usado pelas mulheres Karipuna e Galibi Marworno e traduzido por elas por "mãe do corpo", "mãe do filho", "mãe do pobre". Definem a mãe do corpo como "útero", assim como Fleischer (2007) ouviu das parteiras de Melgaço, fazendo também referência ao mesmo entendimento em outras regiões do Brasil (Victora, 1999 apud Fleischer, 2007, p. 140). Barroso (2001, p. 106), em sua dissertação sobre as parteiras tradicionais do Amapá, faz uma breve menção ao termo "mãe do corpo" definindo-o, igualmente como "útero", mas também como "uma bola que se forma próximo ao útero da mulher" que cresce durante a gestação e "às vezes no parto quer vir junto com a criança". Mindlin (2002, p. 18) faz referência à tese de Pereira sobre as parteiras tradicionais residentes em favelas de Manaus, para as quais a mãe do corpo é "um componente do corpo feminino sem lugar anatômico preciso

5 Kheuol é a língua falada tanto pelos Karipuna quanto pelos Galibi-Marworno, semelhante ao créole falado na Guiana Francesa, com algumas variações locais. As palavras em kheuol serão grafadas em itálico, segundo a grafia do dicionário organizado por Picanço Montejo (1988). 
que, segundo essa tese, pode movimentar-se pelo corpo todo e exige cuidados e invocações especiais".

De fato, a tradução direta do termo por "útero" tem levado a alguns desentendimentos em relação ao saber biomédico, já que os conhecimentos relativos à mãe do corpo envolvem muito mais que o útero enquanto órgão. $\mathrm{O}$ termo em kheuol para este órgão é mathis e duas interlocutoras definiram a mãe do corpo como no mathis, "nosso útero". Suponho que essa tradução se deve ao entendimento de que a mãe do corpo é o lugar onde o feto "pega" e se desenvolve, "é dali que gera uma criança", disse D. Domingas. A mãe do corpo cresce durante a gestação, acompanhando o crescimento do feto e, após o parto, leva 40 dias para "sarar" e voltar ao seu tamanho e lugar originais. Por isso, afirmam que é tão importante respeitar a quarentena, pensada como um período necessário para curar a mãe do corpo.

Entendo que a noção de mãe do corpo excede essa associação ao útero enquanto um órgão. A mãe do corpo é também definida como uma "força pulsante" central para a saúde feminina: "é a força da mulher", "é tudo da gente", "é a essência da mulher". Scopel (2014, p. 150) também encontrou explicações semelhantes entre os Munduruku:

A mãe do corpo era uma força importante para a saúde da mulher Munduruku no dia a dia, e foram especialmente as práticas de autoatenção ao parto que me fizeram notar sua centralidade na vida dessas mulheres. Puxar a mãe do corpo é fundamental para realizar um bom parto. [...]. Itamar explicou que: "a mãe do corpo é uma espécie de saúde da mulher...".

Durante pesquisa de campo realizada em 2010 entre as mulheres Galibi-Marworno, entendi que a mãe do corpo se referia a uma força pulsante, localizada na região do umbigo, na mulher, e no saco escrotal, no homem, um princípio vital que garante a saúde e bem-estar da pessoa e que, caso saia do lugar em virtude de trabalhos excessivos ou exposição a certos ventos, poderia gerar dor e infertilidade (Tassinari, 2015). Nesse caso, a pessoa fica dehãje, o que traduziram por "desarrumada", "desarranjada" ou "deslocada". A puxação de barriga se refere a uma técnica para "colocar a mãe do corpo no lugar", restabelecendo a saúde e equilíbrio da pessoa. Informaram-me técnicas distintas para tratar homens e mulheres. Em mulheres grávidas, a puxação de barriga, 
realizada logo pela manhã com o estômago vazio, também é um modo de fazer contato com o bebê, despertando-o e conduzindo-o com as mãos ao lugar do nascimento.

Esse entendimento sobre a mãe do corpo presente nos corpos de homens e mulheres é semelhante às definições encontradas por Sauma (2019, p. 14) entre quilombolas da região de Oriximiná:

Todos os bebês nascem com corpos abertos; à medida que as crianças crescem, a sua mãe do corpo - órgão que regula a circulação de nutrição e força no corpo - é fixada em seu umbigo, e com isso as suas consciências se desenvolvem, fechando o corpo e diminuindo a vulnerabilidade da pessoa.

Fernando Fileno (2017, p. 18), a respeito dos Mura da região de Borba, também define a mãe do corpo ou "mãe do centro" de modo semelhante:

É tipo um coração porque fica pulsando, descrita a princípio como um órgão, ela também é uma entidade. Desde que nascem, homem e mulher já a dispõe internamente, carente de atenção e cuidado especializado, dela dependem a saúde e a vida do indivíduo.

No entanto, durante a pesquisa de campo realizada em 2016, com mulheres Karipuna e Galibi-Marworno, a ideia de que homens também tivessem mãe do corpo apareceu como absurda, gerando gargalhadas. A mãe do corpo foi apresentada, dessa vez, como exclusiva dos corpos femininos e relacionada somente à saúde da mulher. Pode ter havido um deslizamento semântico desse conceito, talvez para adequar a noção de mãe do corpo à sua definição como "útero". Mas creio que a ideia de que homens e mulheres podem ficar dehãje, e meu parco conhecimento de kheuol, tenham me levado a compreender erroneamente que, para os Karipuna e Galibi-Marworno, ambos têm mãe do corpo.

Em 2020, voltei a entrevistar D. Graziela, uma das mais experientes mulheres que sabem puxar barriga, que ensinou várias gerações de parteiras Karipuna e Galibi-Marworno. Ela reforçou que a mãe do corpo é uma força pulsante feminina, localizada na região do umbigo, responsável pela saúde da mulher. Se ela se desloca da sua posição, a mulher fica dehãje, sentindo dores, ansiedade, mal-estar, não sendo mais capaz de engravidar. O homem também pode ficar 
dehãje, se o seu ghen sair do lugar. Ghen é o termo em geral para "grão, semente ou caroço" (Picanço Montejo, 1988, p. 41), nesse contexto definido por D. Graziela como uma pequena bola como um ovo de codorna localizada no saco escrotal. O tratamento halevã para os homens é diferente, as massagens são feitas na região do baixo ventre, ao lado da crista ilíaca, no sentido de baixo para cima, onde se sentem "pequenos botões" (glã) que não podem descer para o saco escrotal, o que provocaria inchaço, muita dor, podendo levar à morte.

A conversa com D. Graziela juntou toda a família, para melhor traduzir e definir esses termos. Alessandra e sua mãe Marlene, neta e filha de D. Graziela, afirmaram que a mãe do corpo era associada ao útero. Marlene é técnica de enfermagem no hospital do Oiapoque, e acompanhava a mãe nos cursos de parteiras oferecidos pelo estado do Amapá, para servir-lhe de intérprete. Já a nora Cassia Lod explicou que, entre seu povo Galibi-Kaliña, o que chamam de mãe do corpo não é o útero, "é mais um sistema, uma força que tem que estar no lugar para a pessoa estar bem". Por fim, o genro Wanderson, neto de uma experiente parteira Karipuna e aluno da UNIFAP, definiu a mãe do corpo e o ghen como a "essência" da mulher e do homem, respectivamente. Se estiverem fora do lugar, a pessoa fica dehãje.

Entendo que "estar com a mãe do corpo no lugar", ou o ghen, no caso dos homens, diz respeito a um estado de equilíbrio, saúde e integridade da pessoa, antônimo do estado dehãje. Nota-se que esse termo pode também ser usado em outras situações. Se o pai não segue o resguardo e pega peso, por exemplo, pode provocar que o bebê fique dehãje. Assim também, uma parte do corpo que se desloque pode ser considerada dehãje. Para todos esses casos, há diferentes técnicas de puxação.

Nessa interessante "entrevista em família" estavam presentes três gerações e três grupos étnicos (Karipuna, Galibi-Marworno e Galibi-Kaliña), produzindo explicações e traduções que dialogavam com conhecimentos advindos também de diferentes formações acadêmicas (Técnica em Enfermagem e Licenciatura Intercultural Indígena). Fica claro que uma definição abstrata da mãe do corpo foi se construindo, articulando diferentes saberes locais e acadêmicos. Compreendi, porém, que para as mulheres experientes em puxar barriga não é relevante definir a mãe do corpo, como minha ansiedade antropológica buscava. O que importa é saber sentir a sua pulsação e colocá-la no lugar, aliviando as dores das mulheres ou direcionando os bebês para o nascimento. 


\section{Uma rede de mulheres experientes}

Neste item trato da rede de aprendizagem e cooperação na qual se constroem e se disseminam os conhecimentos e práticas das mulheres Karipuna e Galibi-Marworno tratados neste artigo. Essa rede de relações de mulheres experientes extrapola a pertença a aldeias ou etnias e abarca agentes do sistema público de saúde, tanto de forma conflituosa quanto colaborativa.

Um pouco da história da região do baixo rio Oiapoque e do vale do rio Uaçá se faz necessário para explicar a formação dessa rede supraétnica de mulheres experientes em puxar barriga e partejar que, até meados do século $\mathrm{XX}$, foram responsáveis por trazer ao mundo a quase totalidade dessa população.

A população Karipuna, com 2297 pessoas, segundo o último censo do IBGE (cf. Instituto Brasileiro de Geografia e Estatística, 2012), está na sua maioria localizada ao longo do rio Curipi (além de aldeias no rio Oiapoque e na rodovia BR-156). A população Galibi-Marworno tem 1862 pessoas, sendo a maioria residente ao longo do rio Uaçá (além de aldeias na BR-156). Apesar dos constantes casamentos interétnicos e intensa mobilidade entre as aldeias, reconhecem-se como povos distintos, com base em diferentes regras de parentesco e sistemas cosmológicos.

Em trabalhos anteriores (Tassinari, 2003, 2011), com base em dados históricos, procurei mostrar que são descendentes de famílias que experimentaram histórias comuns de violência, escravidão e migrações forçadas durante os séculos XVII e XVIII, gerando deslocamentos, fugas e reduções em missões jesuíticas. Ascendentes das famílias Karipuna, falantes de nheengatu, foram provavelmente "descidos" para as missões jesuíticas portuguesas no baixo rio Amazonas, enquanto os ancestrais dos Galibi-Marworno foram provavelmente reduzidos nas missões jesuíticas francesas no baixo rio Oiapoque, onde povos Aruã, Maraon e Galibi foram agrupados e usavam o Galibi como língua geral. Após o fechamento das missões e expulsão dos jesuítas, no final do século XVIII, essas famílias retornaram para seus antigos territórios no baixo rio Oiapoque e estabeleceram aldeias nos rios Curipi e Uaçá. Explicam que a identidade comum como "batizados" permitiu intercasamentos entre essas famílias, apesar de suas diferentes língua e origens, enquanto evitavam relações com as outras populações locais "não batizadas" como os Aruak, Arakare, Urukuyan e Palikur (Tassinari, 2003). 
Apesar de se reconhecerem como povos distintos e seguirem diferentes regras de parentesco, os Karipuna e Galibi-Marworno têm estabelecido alianças entre si há muitas gerações, produzindo interconexões entre as famílias vivendo nas suas várias aldeias. Os Galibi-Marworno proíbem a endogamia no âmbito de dois grupos, que chamam de hã e has. O hã é a família extensa derivada do padrão uxorilocal de residência: um conjunto de casas de irmãs vivendo com seus maridos e filhos perto da casa dos pais e irmãos solteiros. Esse grupo doméstico chamado de hã é o local onde as crianças crescem e brincam juntas, consideradas entre si como irmãs. Chamam de has o grupo de descendência patrilinear que, apesar de viver em diferentes $h a \tilde{a}$, podem ou não ter frequentes visitações e ocasiões para as crianças brincarem juntas. Do ponto de vista da criança, elas brincam no hã com seus irmãos e primos paralelos matrilaterais, com os quais não poderão se casar. Mas há também interdição de casamento com os primos paralelos patrilaterais, que são da mesma has, ou mesmo com primos cruzados, se também brincarem juntos (Codonho, 2007). Nesse sentido, estando fora desses dois grupos exogâmicos, os Karipuna podem ser potenciais afins para as famílias Galibi-Marworno.

Por outro lado, entre os Karipuna, os padrões de casamento derivam de dois princípios, que devem ser corretamente equilibrados: uma valorização em "misturar o sangue" e um esforço para "não deixar o sangue espalhar" (Tassinari, 2003). O primeiro princípio produz um movimento voltado para fora e uma valorização de casamentos com famílias (ainda) não aparentadas, como os Karipuna de outras aldeias, os Galibi-Marworno ou mesmo com não indígenas. O segundo princípio estimula alianças endogâmicas, que podem incluir primos paralelos e alianças avunculares (consideradas incestuosas pelos Galibi-Marworno). O resultado da articulação desses dois princípios é um padrão no qual uma aliança inicial "mistura" famílias não aparentadas gerando um movimento subsequente de "não espalhar o sangue", repetindo alianças entre essas duas famílias.

Através desses diferentes princípios, a valorização Karipuna em "misturar o sangue" e a exogamia dos grupos hã e has dos Galibi-Marworno, tem sido possível o estabelecimento de alianças interétnicas entre eles, em paralelo à manutenção de suas diferenças como povos distintos. Considero que essa "abertura para a exterioridade" que norteia seus sistemas de parentesco é também característica de seus modos de ensinar e aprender, como pude observar ao analisar as redes de formação das mulheres experientes em puxar barriga. Há um interesse e uma valorização nos conhecimentos exógenos. 
Amparada na abordagem de Lévi-Strauss (1993) a respeito da mitologia ameríndia e sua característica "abertura para o outro", já utilizada para analisar experiências de escolarização indígena (Tassinari; Cohn, 2009), entendo que essa "abertura para a alteridade" é uma importante característica de seus modos próprios de ensino e aprendizagem. Estes valorizam ou destacam a inclusão de um elemento externo, que pode ser tanto o conhecimento aprendido com afins ou estrangeiros (como as práticas de puxar barriga), ou saberes "outros" provenientes de diferentes "donos" (como no caso do xamanismo), ou outras formas de transmitir conhecimentos (como a escolarização, os museus, os vídeos, a internet). Calavia, Carid e Perez (2003) também observam essa valorização dos saberes exógenos entre os Yaminawa.

Nesse caso, a aprendizagem e difusão das técnicas de puxar barriga está muito relacionada a essa busca de uma expertise que extrapola os conhecimentos aprendidos na esfera doméstica. Isso porque, de certo modo, toda mulher Karipuna ou Galibi-Marworno domina os conhecimentos relacionados à mãe do corpo e está pronta a partejar, se for necessário, na medida em que já acompanhou vários partos de suas tias, irmãs ou vizinhas. Como também observou Scopel (2014) sobre os Munduruku, trata-se de conhecimentos mobilizados no cotidiano e nas práticas de autoatenção das famílias.

Durante a pesquisa realizada em 2010, a aldeia de Kumarumã tinha cerca de 1600 pessoas. Havia 9 mulheres reconhecidas pelos seus conhecimentos e habilidades em puxar barriga e fazer partos, outras 3 eram reconhecidas por puxar barriga, mas não faziam partos, e havia 5 mulheres que estavam aprendendo a ser parteiras. A maior parte dessas mulheres (11) eram filhas de parteiras, mas, quando perguntadas com quem aprenderam essas técnicas, menos da metade indicou ter aprendido com sua mãe (5). Outras disseram que aprenderam "da própria cabeça" (3), valorizando os esforços pessoais de observar e memorizar as técnicas. Algumas falaram que aprenderam com outras parteiras: uma tia (2) uma senhora vinda do Curipi (2), uma cunhada, uma prima, uma senhora do Oiapoque, a sogra ou uma irmã da sogra.

É como se, para as mulheres Galibi-Marworno, acompanhar a mãe ou a irmã nas suas atividades cotidianas de puxar barriga fosse algo tão corriqueiro que não merecesse destaque. Ao contrário, o esforço pessoal em observar e aprender "da própria cabeça" ou em buscar outras técnicas com afins, como a sogra ou a cunhada, ou com pessoas de fora, é que foi mais valorizado nos seus discursos. 
Considerando que uma mulher Galibi-Marworno passa a maior parte da vida no interior do hã um espaço de identidade e semelhança, parece que há uma valorização das técnicas aprendidas fora desse contexto.

Em 2016, quando trabalhei com as mulheres Karipuna no rio Curipi, percebi que faziam parte de uma mesma "comunidade de prática" (Lave; Wenger, 1991) das parteiras Galibi-Marworno, no sentido que estavam relacionadas por laços de parentesco e, em diferentes momentos, fizeram parte das mesmas equipes ou acompanharam uma mesma mulher experiente em suas atividades para aprender. Essa rede de mulheres experientes se espalhava pelas aldeias Karipuna e Galibi-Marworno, sendo que uma delas estava puxando a barriga na cidade de Oiapoque, atendendo mulheres indígenas e não indígenas.

Pelo que pude recuperar, tentando traçar linhas de aprendizagens, há uma grande valorização dos conhecimentos trazidos por uma senhora negra de nome Ramira, proveniente do Cassiporé, que passou alguns anos na localidade Tucão, próxima do Encruzo. A essa senhora Ramira as mais antigas atribuem o ensino das técnicas de puxar barriga que utilizam hoje.

Esse conhecimento de puxar barriga eu aprendi com a minha irmã mais velha, a Dorica, ela que me ensinou, eu estava bem novinha, com 15 anos fiz o meu primeiro parto [...] Ela aprendeu com uma parteira que chamavam Ramira, uma cassipeira, que era parenta do marido da Dorica. Eles ficaram ali no Encruzo, num lugar que chama Tucão, é embaixo do Karipurá um pouquinho. Então ela morou lá, aí ela aprendeu com essa médica, né, porque pra gente, uma boa parteira é uma médica. (Entrevista com D. Xandoca, aldeia Santa Isabel, 30/01/2016).

Os conhecimentos ensinados por D. Ramira se espalharam entre as mulheres Karipuna e Galibi-Marworno, a partir de suas aprendizes, que viveram ou passaram uma temporada na mencionada aldeia Karipurá, atualmente desativada. Muitas dessas aprendizes foram responsáveis, juntamente com os esposos, pela fundação de novas aldeias. D. Frozina e o esposo Sabá fundaram a aldeia Açaizal. D. Delfina e o esposo Coco fundaram a aldeia Santa Isabel. D. Dorica, mencionada na citação acima, ensinou para D. Davina, fundadora da aldeia Manga, com seu esposo Florêncio. D. Cadi era Galibi-Marworno, mas casou-se com Alexandre Marcolino do Karipurá, onde morou e aprendeu as técnicas de puxar barriga, que depois ensinou em Kumarumã. Há, portanto, ao menos entre os 
Karipuna, uma clara correlação entre fazer parte do casal fundador de novas aldeias e dominar técnicas de puxar barriga e partejar.

A compreensão dessa rede de aprendizagens, trocas e ajuda mútua é importante para complexificar a ideia comumente difundida de uma aprendizagem de parteiras que ocorre "de geração a geração" (Barroso, 2001; Capiberibe, 2002). Embora a transmissão geracional seja um elemento importante para a aprendizagem desses saberes, é importante reconhecer o movimento de circulação dessas técnicas e conhecimentos entre coetâneas, com ênfase na ação das aprendizes em buscar aprimorar seus conhecimentos, através da experiência e de novas parcerias.

A partir de 1996, essa rede de mulheres experientes do Uaçá que, como vimos, sempre estiveram abertas a novos aprendizados, passa a se articular com o Programa das Parteiras Tradicionais, do governo do Amapá. Algumas dessas mulheres experientes participam dos cursos de formação e reuniões, como o I Encontro Internacional das Parteiras da Floresta, realizado em 1998. Esses cursos e encontros criaram espaços de troca e formação para parteiras indígenas, quilombolas e ribeirinhas de vários municípios amapaenses, inserindo-as também em redes mais amplas, como a Rede Nacional de Parteiras (Mindlin, 2002). Através de parcerias, como a ONG Cais do Porto e a Unicef, foram oferecidos diversos cursos de formação, oferecidos crachás de identificação para atendimentos em hospitais e unidades de saúde ${ }^{6}$ e distribuídos "kits parteiras" com instrumentos e materiais de higiene. Mas esse movimento não se deu sem ambiguidades, conforme tratado no próximo item.

\section{Halevã: a puxação de barriga}

A puxação é uma técnica mais geral de massagens ou procedimentos corporais feitos para restabelecer o equilíbrio e saúde da pessoa. Uma perna ou braço deslocados (dehãje) podem ser recolocados no lugar através da puxação.

6 O objetivo do Programa de garantir o reconhecimento das parteiras tradicionais pelo Sistema Único de Saúde (SUS) chegou a ser alcançado em alguns municípios e Barroso (2001) cita parteiras contratadas pelas prefeituras dos municípios de Mazagão e Santana que faziam partos nas Unidades Mistas de Saúde. Em 2001, foi inaugurada na cidade de Oiapoque a primeira Casa de Parto da Amazônia (Capiberibe, 2002). 
Músculos enrijecidos ou paralisados da face ou dos membros também podem ser puxados para que restabeleçam o movimento.

Mas os conhecimentos das mulheres experientes em halevã, puxar barriga, dizem respeito ao equilíbrio mais geral da pessoa e são práticas terapêuticas para curar um estado dehãje que pode acometer homens, mulheres e crianças. Como vimos, essa condição decorre de um deslocamento da mãe do corpo, no caso das mulheres, ou do ghen, no caso dos homens, que pode ser provocado por trabalho excessivo, exposição a certos ventos, quedas ou movimentos bruscos. No caso de crianças pequenas, o estado dehãje pode ser provocado pelos pais, se não respeitarem cuidados relacionados aos períodos da quarentena ou outras atividades, como a caça.

Explicaram-me que o estado dehãje provoca não apenas dores na região do abdômen e quadril, mas também uma sensação mais geral de mal-estar, preocupação, tristeza, que, se não tratado, pode levar à morte. Por isso, ao sentir essas dores, as pessoas procuram as mulheres experientes em halevã, em suas casas, geralmente ao final de um dia de trabalho. $O$ tratamento é feito ali mesmo, a paciente se deita no assoalho da casa sobre uma toalha ou pano de rede e as mulheres experientes utilizam óleos vegetais, como andiroba, cobaíba ou tucumã, para fazer as massagens no ventre. Às vezes, puxam também pernas e braços da paciente, esticando cada um dos dedos, numa operação que leva entre dez e quinze minutos. Se observar que, ao final do tratamento, a mãe do corpo não voltou totalmente ao seu lugar, a senhora que faz o halevã propõe a continuidade das puxações nos dias seguintes.

Em janeiro de 2010, acompanhei as puxações feitas numa jovem senhora, mãe de um filho adolescente, que queria engravidar novamente e não conseguia. Ela combinou um tratamento com uma experiente parteira e sua filha, que estava aprendendo a arte de halevã, para colocarem sua mãe do corpo no lugar. De manhã e de noite, essas especialistas iam até a casa da paciente para puxar sua barriga, num evento que acabava reunindo também as outras mulheres da casa: sua mãe e sua irmã. Eram momentos de troca entre elas, quando se compartilhavam angústias e temores, as mulheres experientes e a mãe davam conselhos para as filhas, lembravam de outras mulheres que passaram por problemas semelhantes e depois conseguiram engravidar, criando uma atmosfera de confiança e apoio. Ao final de alguns dias, observando que a mãe do corpo se acomodara em seu lugar, foi feita a técnica para "amarrar a mãe do corpo": 
colocando o dedo indicador no umbigo da paciente e girando-o por três vezes, proferindo palavras próprias para essa "amarração".

No caso das gestantes, elas geralmente procuram as especialistas em halevã quando o bebê começa a mexer e se colocar em posições desconfortáveis, causando-lhe dores, o que se dá por volta do quinto mês. A puxação de barriga, nesses casos, tem outra finalidade: acompanhar o crescimento do feto, observar sua posição, posicioná-lo corretamente para nascer. As especialistas e as gestantes compartilham conhecimentos comuns sobre a importância dessa prática. Contaram que deve ser realizada logo cedo pela manhã, com o estômago ainda vazio. Em geral, é um momento em que o bebê se movimenta pouco, mas dizem que "acorda" e começa a se mexer respondendo ao toque das mãos da especialista. Nesse caso, além dos óleos vegetais mencionados, também podem usar banha de animais como mucura e arraia, que têm seus filhos com muita facilidade. D. Conceição diz que a criança no útero percebe o halevã "eles parecem que ficam animados" (entrevista em 20/01/2016, aldeia Manga).

As mulheres experientes em halevã explicam que essa técnica é fundamental como preparação para um bom parto. Na verdade, o momento do parto é quase secundário em relação a essa preparação. Por volta dos seis meses, quando o feto já está mais crescido, as mulheres que sabem puxar barriga observam, através do toque das mãos, sua posição, a vitalidade de seus movimentos, seu tamanho. Também direcionam sua cabeça para a posição correta do nascimento. Sabem que, nessa fase, o feto não vai ficar imóvel até a data do nascimento, podendo mudar de posição. Mas parece que há aí um entendimento de que é possível ir direcionando-o para a posição correta para nascer. D. Graziela explicou que a parteira "mostra", "indica", "dirige" o bebê para o lugar certo. Entendo isso como um exemplo de "esquema" mencionado por Toren (2014), que o bebê apreende a partir das sensações provocadas pelo toque da especialista no ventre materno.

Como vimos, desde 1996, algumas mulheres experientes em puxar barriga e partejar começaram a frequentar os cursos de formação do Programa Parteiras Tradicionais do estado do Amapá. Não é minha intenção aqui fazer uma apresentação do projeto ou discuti-lo, senão pelo que se reverbera dele na fala de minhas interlocutoras. O que se passou, nas aldeias Karipuna e Galibi-Marworno, é que algumas das mulheres experientes em halevã foram cadastradas enquanto "parteiras tradicionais". Até então, a própria noção de "parteira" 
lhes era alheia, sendo reconhecidas como fam ki savê halevã, "mulheres que sabem puxar barriga". Muitas valorizam os encontros, enquanto momentos de trocas de conhecimentos entre "parteiras tradicionais" de todo o estado do Amapá. Mas geralmente se ressentem pela maneira como seus conhecimentos são tratados nesses encontros, desestimulando algumas práticas - especialmente o halevã, estabelecendo rotinas diferentes, tratando com desconfiança suas noções de higiene. Situações semelhantes foram observadas por Fleischer (2007) junto às parteiras de Melgaço (PA), por Barroso (2001) em quatro municípios do Amapá e por Cardoso e Nascimento (2019) entre parteiras do município de Santana (AP).

Ao serem cadastradas como "parteiras tradicionais", algumas mulheres experientes em puxar barriga passaram a receber uma quantia mensal e a ter que preencher relatórios indicando o número de partos realizados e de mulheres atendidas em "pré-natal". Esse passou a ser o termo para o que se fazia antes como visitas para puxar a barriga das gestantes. Porém, a própria puxação passou a ser tratada com desconfiança e desestimulada. Enquanto as parteiras mais antigas e autoconfiantes continuaram a realizar normalmente suas atividades, as aprendizes mais jovens passaram a ser formadas com receio de levarem a mãe ou o bebê a óbito. Uma reclamação geral nas comunidades é que, atualmente, com a diminuição da prática de halevã, está crescendo o número de partos encaminhados ao hospital de Oiapoque.

A técnica de enfermagem (não indígena) que trabalha desde 2008 na aldeia Manga explicou que o sistema de saúde local procura respeitar as parteiras, considerando que as gestantes se sentem à vontade com elas. Mas não considera as suas técnicas eficazes, inclusive apresentou várias preocupações em relação a algumas práticas:

$\mathrm{O}$ atendimento delas, em questão da cultura, a gente tem que respeitar. $\mathrm{O}$ parto é realizado sempre com sucesso, né, quando não dão conta elas chamam a gente. [...] O que a gente bate muito com as parteiras é a questão da prevenção, de um tétano, de uma infecção, a gente tem um pouco de dificuldades com elas em relação a usar luva. Elas têm o costume delas, não querem usar luva. Tem os unguentos delas que usam, puxam a barriga, passam na parte íntima das grávidas. Elas têm todo esse processo. [...] O óleo que elas usam, às vezes acontece edema vaginal. Elas dizem que a andiroba ajuda na dilatação, mas os médicos 
dizem que não interfere em nada. (Entrevista com M., técnica de enfermagem, aldeia Manga, 23/01/2016).

Aqui se nota uma relação conflitiva entre os conhecimentos das mulheres que sabem puxar barriga e o sistema público de saúde, mesmo com muitos profissionais indígenas atuando como técnicos de enfermagem, tanto nas aldeias como na cidade de Oiapoque. É necessário assinalar que a supervalorização dos conhecimentos da biomedicina, a tradução simplificada dos conceitos locais para termos biomédicos, a desconfiança dos saberes de mulheres anciãs e suas noções de higiene e a insegurança provocada nas jovens aprendizes têm ameaçado fortemente a manutenção da prática do halevã.

\section{Cuidados na hora do parto, puerpério e quarentena}

Mesmo com tudo isso, na hora do parto, as gestantes preferem estar com uma mulher experiente em sua casa do que na enfermaria ou no hospital. Uma jovem Galibi-Marworno, estudante da UNIFAP, contou que na hora do parto preferiu voltar para a sua aldeia, apesar da equipe de saúde ter tratado sua escolha como absurda. Ela insistiu e tudo correu bem no seu parto, feito pela avó.

Para partejar, as mulheres experientes costumam trabalhar em equipes. Há a parteira principal, que vai segurar a criança, mas é importante contar com a ajuda de outras, mais ou menos experientes, para segurar a parturiente pelas costas, para preparar os chás, para fazer massagens. O parto pode durar muito tempo, por isso também dizem que é melhor trabalhar em grupo. Apanham sete folhas da cuieira que estão já caídas no chão e preparam um chá para aumentar as contrações. Puxam a barriga com óleo de andiroba, que também passam no canal vaginal para ajudar na dilatação. Preparam um chá de pimenta e/ou gengibre, para dar força para a mãe e para o feto. A força do feto é reconhecida como elemento importante para seu nascimento e alguns chás e massagens têm o intuito de "animar o bebê para nascer". Como vimos, essa "força que faz nascer" vem de sua nam.

Após o nascimento da criança, espera-se que a placenta saia inteiramente para cortar o seu cordão umbilical. A placenta é também chamada deãiẽ-fet, que, literalmente, pode-se traduzir como "o último a nascer", sendo também considerada viva e pulsante. As parteiras puxam a barriga da puérpera para ajudar 
a placenta a sair e dizem sentir o seu movimento vivo. Maria José, em Kumarumã, explicou que a parteira passa um punhado de sal no cordão umbilical para facilitar o nascimento da placenta. Aguarda-se que a placenta morra para que seja enterrada próxima da casa, envolta em panos, em uma cova não muito profunda.

D. Xandoca conta que, antigamente, cortavam o cordão com ponta de flecha partida ao meio e amarravam o umbigo com o fio de curauá. Para secar o umbigo, ralavam pó de taperabá na língua do pirarucu e passavam no local. Se não dava certo, usavam pó da paxiúba, leite de pião. Segundo ela, atualmente, o médico não deixa cortarem o cordão do umbigo, tem que chamar o técnico de enfermagem para fazer a assepsia. Mas vimos que, na aldeia de Açaizal, ainda se mantém o costume de dar à mãe, para que ela mesma corte o cordão umbilical do bebê, uma ponta de flecha preparada pelo pai durante a gestação e mantida guardada no beiral de casa. Cortar o cordão umbilical do filho recém-nascido deve ser um exercício importante para essas populações que em tudo respeitam as decisões e autonomia das crianças.

A mãe oferece o peito ao bebê logo depois do nascimento. A amamentação segue a demanda da criança, tanto nesses primeiros dias de vida quanto por todo o período em que mama. Nos casos em que a criança "não pega o peito" da mãe, não consegue começar a mamar, chamam um especialista em sufle, para "soprar" o peito. A técnica do "sopro" pode ser usada em várias circunstâncias na fase do puerpério, para garantir a saúde da mãe e do bebê, especialmente quando a criança tem algum mal-estar atribuído ao não cumprimento das evitações da quarentena por parte dos pais, sejam evitações sexuais, de atividades ou alimentares. Também há "sopros" para as crianças desenvolverem bem a fala, para serem inteligentes e espertas.

As parteiras visitam a puérpera durante oito dias, quando preparam banhos e chás para ela e para o recém-nascido. Para o bebê, preparam um banho com folhas do algodão roxo e cuidam do seu cordão umbilical. O banho de assento da puérpera é chamado de bẽ, feito com "cascas travosas": cascas de andiroba, ucuúba, verônica, caju, manga, anani, capitiú. Barroso (2001) encontrou práticas semelhantes em sua pesquisa realizada com parteiras tradicionais de quatro municípios do Amapá. Dizem que o banho é muito eficaz para a cicatrização interna e externa da região vaginal. Segundo Maria José, que está aprendendo a ser parteira: 
Olha, no curso de parteiras do branco é diferente do índio, porque lá no branco não usa, assim, um remédio caseiro, não usa. E, pra nós aqui, eu acho, que é muito bom e importante e serve, é valioso pra nós. [...] Quando a mulher ganha o bebê, aí passa uns dois dias, três dias, elas faz um banho de casca de pau que é amargo, a mulher senta dentro, assim bem... Aí, isso pra nós, que nem do branco, né, eles dão injeção, benzetacil, pra sarar, né. Então, aqui é diferente, esse banho é muito bom. Essa daí que é a injeção do índio. (Entrevista com Maria José, Kumarumã, 13/01/2010).

Nesses dias após o parto, as especialistas fazem o halevã e "amarram a mãe do corpo", de um modo diferente daquele anteriormente descrito. Dessa vez, utilizam faixas de pano para pressionar o ventre da mulher e deixá-lo firme, de modo que, durante a quarentena, a mãe do corpo retome seu lugar. Nesse período e durante a quarentena, os banhos da mãe e do bebê ocorrem somente dentro da casa e são preparados com água morna.

Nessa fase posterior ao nascimento, quando a criança "abre seus olhos para esse mundo", é preciso tomar uma série de cuidados para protegê-la do ataque de seres invisíveis, para evitar que sua nam se distancie do seu corpo e para garantir que "crie corpo". Além do especialista em sufle (sopro), também chamam benzedeiras, para curar quebranto ou olho gordo, por exemplo, que provocam choro, diarreia, vômito e deixam a criança apática. A apatia também pode ser sinal de que a nam saiu do corpo da criança, por um susto ou por ter se atraído por seres invisíveis que podem leva-la à morte e, nesse caso, somente um pajé consegue chamar a nam de volta.

A quarentena, como vimos, é o período que a mãe do corpo leva para se curar e voltar ao seu lugar. Ermelinda conta que, nessa época, as puérperas não podem comer comidas reimosas ou frutas gordurosas, que podem dar diarreia no bebê. O certo é comer canja e comidas com pouco tempero. Também não podem pegar peso ou fazer atividades diárias, mantendo-se deitadas na maior parte do tempo. Isso só é possível na medida em que outras mulheres as apoiam nessa fase, geralmente as mães ou irmãs. Os pais também fazem a couvade, evitando caçar ou realizar trabalhos pesados. Há uma ideia de que o "peso" pode recair sobre a criança e fazê-la adoecer. Em 2016, Ermelinda estava em quarentena na cidade de Oiapoque, cursando uma etapa presencial da Licenciatura Intercultural Indígena da UNIFAP. Ela decidiu que não iria perder as 
aulas, mas, para respeitar a quarentena, passava o resto do tempo estudando deitada em sua casa.

Para o bebê crescer e ficar gordinho, usam a técnica aple laxe, para "chamar a carne". É uma atividade diária de "moldar" o corpo do bebê através de massagens feitas pela mãe na criança. Sentada no assoalho, com o bebê deitado em suas pernas, a mãe envolve o bracinho do bebê com suas duas mãos e realiza movimentos giratórios em sentidos contrários, fazendo com que a musculatura suavemente deslize sobre os ossos, enquanto emite um som de estalos com a boca. Faz o mesmo com as nádegas, as pernas, as costas, o pescoço, a cabeça e o rosto, modelando o nariz, as orelhas, as bochechas. Chamam esse processo de "fazer o corpo" do bebê, movimento que exemplifica o que foi apontado por Seeger, DaMatta e Viveiros de Castro (1979). Dizem que essa prática é tão importante para o desenvolvimento saudável da criança quanto a alimentação.

Observei que as mães têm muito prazer em fazer aple laxe nos bebês e que essa prática aprofunda o vínculo entre ambos. A criança fica calma e atenta aos movimentos da mãe. Na aldeia Espírito Santo, as mulheres experientes indicam fazê-la três vezes ao dia, de manhã, depois do almoço e no entardecer, junto com o banho, ao longo dos primeiros meses de vida. Essa prática tem início logo após o nascimento, quando é feita com mais frequência, mas tem continuidade durante o primeiro ano de vida do bebê. Para acompanhar o desenvolvimento do bebê, são colocadas pulseirinhas de miçangas nos braços e pés, como uma forma de observar se o bebê está emagrecendo, o que deixaria as pulseirinhas frouxas, ou engordando, o que as deixaria apertadas, precisando aumentar a quantidade de miçangas.

Como vimos, até os três anos, a criança é chamada de tximimi, uma fase em que é considerada dependente de alguém para cuidar. Mesmo assim, reconhecem e respeitam as suas escolhas, principalmente depois que conseguem caminhar e se expressar. Elas acompanham os pais nas atividades diárias e, às vezes, tentam imitá-los, como descrevo em Tassinari (2015), ou acompanham outras crianças maiores em suas brincadeiras, como aponta Codonho (2007), ambos momentos importantes de seus processos próprios de aprendizagem.

Tenho procurado mostrar (Tassinari, 2016) que se trata de uma pedagogia que tem a liberdade como princípio e a autonomia com meta, na medida em que considera que as crianças devem estar livres na aldeia para "criar corpo", 
"pegar o ritmo da comunidade". Essa liberdade, aliada à responsabilidade pelas escolhas e em virtude das habilidades adquiridas, são condições para a autonomia e uma sensação de autoconfiança que as crianças experimentam ainda muito pequenas. Entendo que os toques das mulheres experientes no ventre das gestantes, indicando o canal do nascimento, e as massagens das mães nos corpos de seus filhos sejam parte dessa pedagogia e elementos importantes para garantir ao feto e recém-nascido uma sensação de segurança, conforto e cuidado em meio às tantas mudanças vividas nos momentos tensos do nascimento e ao longo do primeiro ano de vida.

\section{Considerações finais}

Nestas páginas procurei apresentar os conhecimentos e técnicas utilizados por uma rede de mulheres Karipuna e Galibi-Marworno, a respeito da gestação, parto e puerpério. Essas mulheres, há várias décadas, têm ensinado, curado e apoiado umas às outras, assim como às suas filhas, noras, parentes, vizinhas, sobre as dinâmicas relativas aos seus corpos e à gestação de outros corpos. Através das massagens halevã têm levado alívio às suas dores, conforto para suas angústias, esperanças para suas expectativas de engravidar. Através dos seus conhecimentos em partejar, têm dado suporte físico e emocional para as parturientes, que se sentem seguras em suas mãos. Segurança que, por certo, apreenderam ainda no ventre de suas mães, manipulados por mãos experientes que lhes indicaram o caminho do nascimento.

Suas narrativas sobre os partos bem-sucedidos que realizaram graças às técnicas de halevã não têm sido suficientes para convencer um sistema de saúde que considera essas práticas perigosas e se esforça por reprimi-las, apesar das importantes iniciativas do governo do Amapá de valorizar e profissionalizar as parteiras tradicionais. Segundo Schwarzstein (2002, p. 11), "sabemos que o Amapá apresenta a menor taxa de mortalidade infantil das regiões Norte e Nordeste e que esta taxa situa-se, historicamente, alguns pontos abaixo da média brasileira". Procurei, ao longo do artigo, lançar luz para a hipótese de que esses bons resultados se devam aos trabalhos de mulheres experientes em puxar barriga e partejar. Ressalto a importância do desenvolvimento de pesquisas que permitam um maior diálogo entre conhecimentos biomédicos e as variadas 
noções de pessoa, corporalidade e infância que amparam as puxações de barriga, garantindo sua efetiva compreensão e reconhecimento.

Considero que os dados etnográficos sobre a população Karipuna e Galibi-Marworno, aqui apresentados, contribuem em alguns aspectos. A reflexão sobre o conceito de mãe do corpo, que revelou os problemas decorrentes de uma tradução direta como "útero" e a importância de associá-la a noções próprias de corporalidade, pessoa e gênero. A ampliação do conceito de "infância" para abarcar também a criança que cresce no ventre materno, que acorda e se manifesta a partir do halevã, que é capaz de aprender o caminho do próprio nascimento. A observação de que o parto não é entendido por essas especialistas como momento decisivo e central de suas atividades, mas como o desfecho de um processo que merece cuidados a partir dos cinco meses de gestação, quando o bebê começa a ficar em posições incômodas para a mãe. Finalmente, o reconhecimento de uma rede de mulheres experientes que compõem uma comunidade de praticantes nos termos de Lave e Wenger (1991), através da qual esses conhecimentos não são apenas "passados de geração em geração" como se fossem um repertório fixo, mas são colocados à prova, experimentados, aprimorados, combinados com outros saberes aprendidos em outras redes de mulheres.

Finalizo retomando a importância de "descentrarmos nosso olhar" e nos desapegarmos de expectativas antropológicas por explicações elaboradas ou refinadas ontologias. Essas mulheres me ensinaram que a mãe do corpo não é uma ideia abstrata, mas uma força pulsante que reside na região do nosso umbigo e que nos dá equilíbrio. Assim como seus saberes não se traduzem em exegeses discursivas, mas se espalham pelos corpos através de óleos e massagens, através de banhos mornos e curativos, através de chás estimulantes e terapêuticos. A essas mulheres dedico minha admiração e respeito e espero que este artigo seja uma forma singela de valorizar seu trabalho.

\section{Referências}

BARROSO, I. C. Saberes e práticas das parteiras tradicionais do Amapá: histórias e memórias. 2001. Dissertação (Mestrado em História) - Instituto de Filosofia e Ciências Humanas, Universidade Estadual de Campinas, Campinas, 2001. 
CALAVIA, O.; CARID, M.; PEREZ, L. O saber é estranho e amargo. Sociologia e mitologia do conhecimento entre os Yaminawa. Campos, Curitiba, n. 4, p. 9-28, 2003.

CAPIBERIBE, J. Os anjos da floresta. In: JUCÁ, L.; MOULIN, N. Parindo um mundo novo: Janete Capiberibe e as parteiras do Amapá. São Paulo: Cortez: Unicef, 2002. p. 21-26.

CARDOSO, M. A. S.; NASCIMENTO, R. O dom e a dádiva entre parteiras do Amapá: uma abordagem etnográfica. Saúde e Sociedade, São Paulo, v. 28, n. 1, p. 235-249, jan./mar. 2019.

CODONHO, C. G. Aprendendo entre pares: a transmissão horizontal de saberes entre as crianças indígenas Galibi-Marworno (Amapá, Brasil). 2007. Dissertação (Mestrado em Antropologia Social) - Centro de Filosofia e Ciências Humanas, Universidade Federal de Santa Catarina, Florianópolis, 2007.

COHN, C. Antropologia da criança. Rio de Janeiro: Jorge Zahar Editor, 2005.

FILENO, F. No seio do rio: linhas que casam, que curam e que dançam. Parentesco e corporalidade entre os Mura do Igapó-Açu. 2017. Tese (Doutorado em Antropologia Social) - Faculdade de Filosofia, Letras e Ciências Humanas, Universidade de São Paulo, São Paulo, 2017.

FLEISCHER, S. R. Parteiras, buchudas e aperreios: uma etnografia do atendimento obstétrico não oficial na cidade de Melgaço, Pará. 2007. Tese (Doutorado em Antropologia Social) - Instituto de Filosofia e Ciências Humanas, Universidade Federal do Rio Grande do Sul, Porto Alegre, 2007.

GOTTLIEB, A. Tudo começa na outra vida: a cultura dos recém-nascidos no oeste da África. São Paulo: Editora Unifesp, 2012.

INSTITUTO BRASILEIRO DE GEOGRAFIA E ESTATÍSTICA. Indígenas. In: IBGE. [S. l.]: IBGE, 2012. Disponível em: https://indigenas.ibge.gov.br/apresentacao-indigenas.html. Acesso em: 30 mar. 2020.

LACZYNSKI, P. Parteiras tradicionais do Amapá. Dicas Instituto Pólis, São Paulo, n. 138, 1999. Disponível em: https://polis.org.br/publicacoes/parteiras-tradicionais-do-amapa/. Acesso em: 30 mar. 2020.

LAVE, J.; WENGER, E. Situated learning: legitimate peripheral participation. Cambridge: Cambridge University Press, 1991.

LÉVI-STRAUSS, C. História de lince. São Paulo: Companhia das Letras, 1993.

MINDLIN, B. As parteiras do Amapá. In: JUCÁ, L.; MOULIN, N. Parindo um mundo novo: Janete Capiberibe e as parteiras do Amapá. São Paulo: Cortez: Unicef, 2002. p. 13-20. 
PEREIRA, R. F. Criando gente no alto rio Negro: um olhar waíkhana. 2013. Dissertação (Mestrado em Antropologia Social) - Universidade Federal do Amazonas, Manaus, 2013.

PICANÇO MONTEJO, F. No djisone kheuol-portxige/O nosso dicionário português-kheuol. Belém: Edições Mensageiro, 1988.

PLATT, T. O feto agressivo, parto, formação da pessoa e mito-história nos Andes. Tellus, Campo Grande, ano 9, n. 17, p. 61-109, jul./dez. 2009.

SANTOS, M. R. Sobre o nascer da pessoa indígena: uma análise bibliográfica de teses e dissertações acerca dos processos de gestação, parto e pós-parto indígenas. 2019. Trabalho de Conclusão de Curso (Graduação em Antropologia) - Universidade Federal de Santa Catarina, Florianópolis, 2019.

SAUMA, J. 'Moramos no mundo dos invisíveis': sobreposição, ruptura e movimento em uma área coletiva quilombola. In: STOLL, E. et al. (org.). Paisagens evanescentes: estudos sobre a percepção das transformações nas paisagens pelos moradores dos rios Amazônicos. Belém: NAEA/UFPA, 2019. p. 115-136.

SCHWARZSTEIN, J. A mais antiga profissão do mundo. In: JUCÁ, L.; MOULIN, N. Parindo um mundo novo: Janete Capiberibe e as parteiras do Amapá. São Paulo: Cortez: Unicef, 2002. p. 7-12.

SCOPEL, R. A cosmopolítica da gestação, parto e pós-parto: práticas de autoatenção e processo de medicalização entre os índios Munduruku. 2014. Tese (Doutorado em Antropologia Social) - Centro de Filosofia e Ciências Humanas, Universidade Federal de Santa Catarina, Florianópolis, 2014.

SEEGER, A.; DAMATTA, R.; VIVEIROS DE CASTRO, E. A construção da pessoa nas sociedades indígenas brasileiras. Boletim do Museu Nacional, Rio de Janeiro, n. 32 , p. 2-19, 1979.

TASSINARI, A. No bom da festa, o processo de construção cultural das famílias Karipuna do Amapá. São Paulo: Edusp, 2003.

TASSINARI, A. Concepções indígenas de infância no Brasil. Tellus, Campo Grande, ano 7, n. 13, p. 11-25, out. 2007.

TASSINARI, A. Organização social e história Galibi-Marworno. Um estudo comparativo com os Karipuna. In: CONVEGNO INTERNAZIONALE DI AMERICANISTICA, 33., 2010, Perugia. Atti [...]. Perugia: Centro Studi Americanistici, 2011. p. 1173-1181.

TASSINARI, A. 'A casa de farinha é nossa escola': aprendizagem e cognição galibi-marworno. Política \& Trabalho: Revista de Ciências Sociais, João Pessoa, n. 43, p. 65-96, jul./dez. 2015. 
TASSINARI, A. La liberté comme principe. L'éducation des enfants chez les Galibi Marworno du Brésil et la scolarisation. Cahiers de la recherche sur l'éducation et les savoirs, Paris, n. 15, p. 101-122, 2016.

TASSINARI, A.; COHN, C. 'Opening to the other": schooling among the Karipuna and Mebengokré-Xikrin of Brazil. Anthropology \& Education Quarterly, [s. l.], v. 40, n. 2, p. 150-169, 2009.

TOREN, C. Review: Do Babies Have Culture?. Anthropological Quarterly, [s. l.], v. 77, n. 1, p. 167-179, Winter 2004.

TOREN, C. Antropologia e psicologia. Revista Brasileira de Ciências Sociais, São Paulo, v. 27, n. 80 , p. 21-36, out. 2012.

TOREN, C. What is a schema?. Hau: Journal of Ethnographic Theory, [s. l.], v. 4, n. 3, p. 401-409, 2014.

TORNQUIST, C. S. Parto e poder: o Movimento pela Humanização do Parto no Brasil. 2004. Tese (Doutorado em Antropologia Social) - Centro de Filosofia e Ciências Humanas, Universidade Federal de Santa Catarina, Florianópolis, 2004.

TORNQUIST, C. S. Parteiras populares: entre o folclore e a escuta. Gênero, Niterói, v. 6, n. 1, p. 61-80, 2. sem 2005.

VERÍSSIMO, S. Educação tradicional e o uso da tecnologia na infância Guarani / Kyringue Onheovanga Ha' e Jurua Mba' e Oiporu Onhembo' ea Py. 2020. Trabalho de Conclusão de Curso (Licenciatura Intercultural Indígena do Sul da Mata Atlântica) - Centro de Filosofia e Ciências Humanas, Universidade Federal de Santa Catarina, Florianópolis, 2020.

Recebido: 31/03/2020 Aceito: 29/03/2021 | Received:3/31/2020 Accepted:3/29/2021 